\title{
Understanding dyspnoea by its language
}

\author{
G. Scano**\#, L. Stendardi ${ }^{\#}$ and M. Grazzini ${ }^{\#}$
}

ABSTRACT: Dyspnoea is a general term used to characterise a range of qualitatively distinct descriptors that vary in intensity. Based on the hypothesis that various qualities of respiratory discomfort result from different pathophysiological abnormalities, language could help to define one or more of the abnormalities responsible for breathing discomfort. The use of descriptors of dyspnoea may contribute to the understanding of the mechanisms of dyspnoea, and assist in identifying or predicting a specific diagnosis. Symptoms that can be reliably discriminated imply different pathophysiological mechanisms, whereas symptoms that cannot be reliably discriminated imply similar pathophysiological mechanisms. Since dyspnoea is a fundamental part of patient's clinical history, physicians should become more fluent in the language of dyspnoea.

KEYWORDS: Bronchoconstriction, dyspnoea, verbal descriptors

\section{THE LANGUAGE OF DYSPNOEA}

Dyspnoea is a general term used to characterise a range of qualitatively distinct descriptors that vary in intensity, and are influenced by a wide variety of factors, such as socio-economic status, motivation, affective components, cultural expectations, and a patient's experience and memory $[1,2]$. The use of verbal descriptors of dyspnoea may contribute to the understanding of the mechanisms of dyspnoea, and assist in identifying or predicting a specific diagnosis. Using the descriptors of dyspnoea, SIMON et al. [1] demonstrated that normal volunteers could distinguish between the kinds of dyspnoea induced by different stimuli, such as breath holding, carbon dioxide inhalation, exercise, resistive and elastic respiratory loads, and constrained tidal volume $(V T)$. These individuals found it easy to distinguish the discomfort associated with the different tasks and selected different phrases to describe the discomfort. Descriptors of dyspnoea were also readily obtained in symptomatic patients with different cardiorespiratory diseases. Standardised descriptors were grouped in discrete clusters with high discriminating value among diseases [1]. Multiplicity, uniqueness, and sharing characterise the association of qualitative clusters of dyspnoea with different disease states: 1) the pathological conditions characterised by many clusters suggest that dyspnoea comprises more than one sensation; 2) each condition is characterised by a unique set of clusters; and 3) some clusters are shared by more than one condition, suggesting that similar pathways or receptors modify dyspnoea, respectively. There is no obvious relationship between the qualitative descriptors of dyspnoea and the quantitative intensity among the patient groups; a cluster may be shared by a disease with the highest and lowest intensity of dyspnoea. In contrast, diseases with the highest scores of dyspnoea may have different patterns of clusters. Thus, the quality of the sensation, not the quantity of intensity, differentiates the diseases [1].

ELLIOT et al. [2] examined 45 descriptors of breathing discomfort in 169 patients considered to provide reliable information; they confirmed the data by SIMON et al. [1] and again suggested that there are many distinct sensations involved in the concept of dyspnoea. Based on the hypothesis that various qualities of respiratory discomfort result

Previous articles in this series: No. 1: Man WD-C, Moxham J, Polkey MI. Magnetic stimulation for the measurement of respiratory and skeletal muscle function. Eur Respir J 2004; 24: 846-860. No. 2: Farré R, Montserrat, JM, Navajas D. Noninvasive monitoring of respiratory mechanics during sleep. Eur Respir J 2004; 24: 1052-1060. No. 3: Calverley P.M.A., Koulouris N.G. Flow limitation and dynamic hyperinflation: key concepts in modern respiratory physiology. Eur Respir J 2004; 24: 186-199

European Respiratory Journal Print ISSN 0903-1936 Online ISSN 1399-3003

\section{AFFILIATIONS}

*Dept of Internal Medicine, Respiratory Disease Section, University of Florence, and \#Fondazione Don C. Gnocchi, Istituto di Ricerca e Cura a Carattere Scientifico, Pozzolatico Florence, Italy.

CORRESPONDENCE

G. Scano

Dept of Internal Medicine Section of Clinical Immunology Allergology and Respiratory Disease University of Florence Viale Morgagni 87 50134 Firenze Italy Fax: 39055412867 E-mail: g.scano@dmi.unifi.it

Received:

May 192004

Accepted after revision:

November 122004 
from different pathophysiological abnormalities, language could help to define one or more of the abnormalities responsible for breathing discomfort. Some tests of cluster validity have been performed. ELLIOT et al. [2] found that the repeatability of their list of descriptor items was reasonably good, although a number of items were rather unstable. BANZETT et al. $[3,4]$ found agreement of descriptor clusters in quadriplegic patients and curarised normal subjects. Test-retest reliability was satisfactory for the dyspnoea descriptor selection, and those selected after recall were similar to those selected after moderate exertion in chronic obstructive pulmonary disease (COPD) [5]. Therefore, it becomes increasingly evident that using dyspnoea descriptors can assist medical nurses and caregivers in understanding the language of dyspnoea.

However, it cannot be assumed that all individuals share a common understanding of the same descriptors. Differences in languages, races, cultures, and the manner in which concepts or symptoms are held can all influence a subject's perception of dyspnoea. For example, there are no simple descriptors in Italian for symptoms easily identified in English, such as breathlessness and dyspnoea [6]. Furthermore, as reported by JONES et al. [7], Peiffer and colleagues in France were not able to replicate the descriptor clusters found by ELLIOTT et al. [2]. A model for studying the language of dyspnoea should be based on a population that is comparable with the individuals being evaluated [8].

The following is a list of clusters of dyspnoea most commonly selected by patients with respiratory disorders.

\section{Chest tightness}

"Chest tightness" is frequently reported by asthmatic patients. At the Hering-Breuer Centenary Symposium, London, UK, PETIT [9] reported that the sensation of chest tightness induced by acute bronchoconstriction receded after vagal blockade. During acute bronchoconstriction, chest tightness may arise from the stimulation of sensory receptors within the lungs mediated through vagal and autonomic pathways. Slowly adapting receptors are excited by contraction of airway smooth muscle; rapidly adapting (irritant) receptors and C-fibres may respond to local inflammation of the airways [10]. Support for this hypothesis comes from the fact that airway anaesthesia with lidocaine reduces the sensations of chest tightness associated with histamine-induced bronchoconstriction, leading to the conclusion that vagal activity contributes to the sensation of chest tightness [11].

\section{Work/effort}

Descriptors comprised in the cluster "work/effort" are selected as common for most diagnoses and characterise several clinical conditions [1]. Regardless of the specific disorder, work/effort intensifies during exercise. The increase in motor command to ventilatory muscles relayed by interneurons high in the central nervous system to the sensory cortex (corollary discharge) can be perceived as a sensation of effort [12-15]. The intensity of the motor command alone, or in combination with the generation of force and contraction of the respiratory muscles, may be consciously appreciated as difficult breathing [16]. Therefore, the respiratory muscles are important to the experience of dyspnoea. The score of effort decreases with assisted ventilation as compared with spontaneous breathing, during methacholine ( $\mathrm{MCh}$ )-induced bronchoconstriction [17].

\section{Unrewarded inspiration}

The central motor command output to the sensory cortex (the corollary discharge) is modulated by a peripheral feedback from a host of respiratory mechanoreceptors that provide precise kinesthetic information about inspiratory muscle displacement (muscle spindles), tension development (Golgi tendon organs), changes in respired volume and flow, and airway calibre (vagal lung and airway mechanoreceptors) [16]. The relative contribution of these receptors to the perception of intensity and quality of respiratory sensations in induced bronchoconstriction and hyperinflation has only recently been elucidated. In patients with low cervical quadriplegia, the quality and intensity of dyspnoea during $\mathrm{MCh}$-induced bronchoconstriction and dynamic hyperinflation were similar to that in asthma at maximal response and not altered by extensive chest wall de-afferentation [18]. The disparity between respiratory motor output and the mechanical response of the system is thought to play a major role in the increased perception of exercise dyspnoea in patients with COPD [19-21] and interstitial lung disorders (ILD) [22]. Reduced lung volumes and increased respiratory drive account for the imbalance between the increased central output and the probable reduced instantaneous peripheral feedback from the lung and chest wall [19-22].

\section{Rapid breathing}

When healthy subjects exercise with external thoracic restriction, they frequently identify inspiratory difficulty as "rapid" and "shallow" as appropriate descriptors of their respiratory discomfort $[1,2,5,23]$. Rapid breathing also characterises the exercise response in patients with ILD [22]. The increased respiratory drive results in increased respiratory frequency because of inadequate lung distensibility. Vagal afferents are potentially implicated. Chest compression and lung deflation could potentially reduce the input from stretch receptors with resultant tachypnoea, and simultaneously increase the input of rapidly adapting vagal receptors, which increase respiratory drive and ventilation, thus contributing to dyspnoea [24, 25].

\section{Air hunger}

Hypercapnia drives breathing and, therefore, must influence the perception of motor events. The hypothesis that dyspnoea is largely a sense of respiratory effort does not account for the findings that, at a comparable level of ventilation, dyspnoea is greater during hypercapnic hyperpnoea than exercise hyperpnoea [26]. Changes in dyspnoea increase when the difference in alveolar carbon dioxide tension $\left(\mathrm{PCO}_{2}\right)$ between hypercapnia and exercise rises for similar levels of ventilation. A rise in arterial carbon dioxide tension $\left(\mathrm{Pa}_{\mathrm{a}} \mathrm{CO}_{2}\right)$, such as when holding one's breath, results in an urge to breathe and is easily recognised. DEMEDIUK et al. [27] have shown that the urge to breathe at a constant level of ventilation increases with increasing $\mathrm{PCO}_{2}$, whilst the sense of effort to breathe decreases. They provided evidence that qualitatively different sensations can result from voluntary (cortical) versus reflex (brainstem) drives to breathe, consistent with the possibility that corollary 
discharge from medullary respiratory centres gives rise to "air hunger", whereas corollary discharge from the cortical motor centre gives rise to a sense of breathing effort [4]. Dyspnoea augments at a constant level of ventilation when the breathing frequency is either voluntarily increased, or decreased with reciprocal changes in $V \mathrm{~T}$ from the spontaneous adopted level [28]. These results are consistent with the possibility that breathing responses to change in chemical drive may be regulated, partially to minimise sensations of respiratory effort and discomfort $[28,29]$.

\section{CLINICAL APPLICATIONS OF THE LANGUAGE OF DYSPNOEA \\ COPD and asthma}

Physiological studies in patients with COPD have primarily investigated the intensity rather than quality of sensations. The effect of the physiological derangement of this condition increases both corollary discharge and central output to skeletal muscles, and probably reduces the peripheral instantaneous feedback from the lung and chest wall receptors. COPD patients, when exercised, report qualitative perceptions of "unsatisfied" or "unrewarded" inspiration, "shallow breathing" and "inspiratory difficulty". These distinct sensations are associated with dynamic hyperinflation and its negative mechanical effects, i.e. threshold load and the uncoupling of the normal association between inspiratory effort and ventilatory output [19-21].

In these patients, hyperinflation during exercise probably contributes more to the mechanical problems than the increase in airflow resistance or decrease in dynamic pulmonary compliance [30]. The important consequence of dynamic hyperinflation is the severe mechanical constraint on $V \mathrm{~T}$ expansion [19, 22].

In patients with asthma, symptoms following MCh inhalation were similar to those experienced during spontaneous asthma $[17,31]$. Of 28 patients with asthma, $50 \%$ chose the descriptions "my chest feels tight" or "my chest is constricted" to describe their dyspnoea, whereas none of the 22 patients with COPD and only $13 \%$ of the 16 patients with ILD selected these descriptors [5]. These findings are in line with the clinical observation that chest tightness is the most probable manifestation of asthma.

LOUGHEED et al. [31] also showed that patients selected two descriptors: the first was associated with airway obstruction, and the second, "inspiratory difficulty", was coincident with the association of increased airway obstruction with hyperinflation. For any given forced expiratory volume in one second (FEV1) decrease, a progressive increase in airway narrowing was associated with a greater shifting in the Borg score of inspiratory difficulty. KILLIAN et al. [6] stated that the many descriptors that characterise bronchial asthma indicate that different pathophysiological mechanisms are potentially in action, and suggested the possibility of distinguishing among them by utilising symptom discrimination. By using Thurstone's law of comparative judgment, they calculated the sensory distance between any two symptoms in discriminal dispersion units. The discrimination analysis showed symptoms (chest tightness and chest pain) that were easily discriminated, whereas other symptoms (breathlessness and air hunger) were not. Symptoms that can be reliably discriminated imply different pathophysiological mechanisms, whereas symptoms that cannot be reliably discriminated imply similar pathophysiological mechanisms. The study by KILLIAN et al. [6] has also shown that dyspnoea is more intense with bronchoconstriction, baseline pulmonary impairment, weight and female sex; furthermore, dyspnoea is less intense with age, bronchial hyperresponsiveness, a low level of fear, coping and adaptation.

In induced asthma, MoY et al. [32] showed that the initial sensation of chest tightness reflects the breathing discomfort resulting from mild bronchoconstriction; with a more severe FEV1 decrease and hyperinflation, the sensation of work or effort of breathing takes place, which may be due to the related inflammatory component of asthma and associated mechanical load on the ventilatory muscles [33]. Therefore, there appears to be two distinct sensations of dyspnoea. The first sensation to be relieved with $\beta_{2}$-agonist treatment is chest tightness, which probably arises from stimulation of pulmonary receptors secondary to bronchospasm. The second, work/effort, is probably associated with both dynamic hyperinflation and more severe airway obstruction. Like patients with asthma, patients with cystic fibrosis select the cluster "tight" [5]. As airway reactivity/bronchoconstriction is a common feature of these diseases, it is possible that the descriptor "my chest feels tight" originates from airway receptors and reflects airway tone. Due to the underlying mechanism, the score of chest tightness does not decrease with assisted ventilation compared with spontaneous breathing during MCh-induced bronchoconstriction; for the same reason, the chest tightness score is higher with bronchospasm and hyperinflation than with ventilatory-induced hyperinflation and positive end-expiratory pressure [17].

The language of dyspnoea is a useful supplement to overall ratings of dyspnoea intensity whilst monitoring the response to bronchodilator therapy in patients with acute asthma. Assessments of the intensity of dyspnoea alone may not accurately reflect the level of persistent airway obstruction. The global rating of dyspnoea, in conjunction with frequencyintensity rating of work/effort, may reflect the persistence of obstruction-inflammation of the airways more clearly than ratings of overall intensity of dyspnoea alone [34]. Thus, attention to the language of dyspnoea would alert healthcare providers to significant remaining airway obstruction, despite improvements in, or resolution of overall dyspnoea when assessed by general rating of the intensity of breathing discomfort [34].

If it is acknowledged that asthma and COPD involve different pathophysiological derangement, it is also conceivable to accept the possibility of different descriptors for the two conditions. HARVER et al. [35] provided preliminary evidence that chest tightness characterises asthma more than COPD. The reported sensitivity of tightness (i.e. the probability of diagnosing asthma in patients who have asthma) was $86 \%$ for asthma and $7 \%$ for COPD; the specificity (i.e. the probability of excluding asthma in patients who do not have asthma) was $69 \%$ and $64 \%$, respectively. The data indicate that $>86 \%$ of patients who report chest tightness have asthma, not COPD, and $\sim 69 \%$ of patients who do not report chest tightness 
do not have asthma. Another descriptor ("I feel I cannot get a deep breath") has high specificity for COPD (72\%), but a lower specificity for asthma $(61 \%)$, and a low sensitivity for both conditions (37\% and 50\%, respectively).

\section{Interstitial/restrictive lung disease}

HARTY et al. [23] and O'DONNELL et al. [36] reported on the pattern of qualitative response selected with thoracic restriction in exercising normal subjects. Subjects frequently identified work/effort, unsatisfied inspiration, inspiratory difficulty, rapid and shallow as appropriate descriptors of their breathing, a set of qualitative responses similar to those reported by patients with restrictive lung disease (RLD) [1, 2, 5, 22]. These sensations have their physiological basis partially in an impaired ability to increase lung volume and displace the thorax appropriately in the setting of an increased ventilatory drive. A slight variation in the patient's average $V \mathrm{~T}$ at rest provokes considerable dyspnoea, and this vulnerability to dyspnoea probably explains why the resting respiratory cycle is so tightly controlled in patients with RLD [29]. Patients display a parabolic or U-shaped relationship between $V \mathrm{~T}$ and dyspnoea: a slight increase or decrease in $V \mathrm{~T}$ from the average resting value causes a marked increase in dyspnoea. The former is associated with greater respiratory work, whereas the latter is associated with increased dead space ventilation and hypercapnia [29]. LANSING et al. [37] found that air hunger rating changes more deeply when $\mathrm{Pa}, \mathrm{CO}_{2}$ is altered and minute ventilation $\left(V^{\prime} \mathrm{E}\right)$ is constant, whereas the work/effort rating changes more deeply when $V^{\prime} \mathrm{E}$ increases and $\mathrm{Pa}_{\mathrm{a}} \mathrm{CO}_{2}$ is constant. The U-shaped curve relating difficulty of breathing to $V^{\prime} \mathrm{E}$, with the $V^{\prime} \mathrm{E}$ at the centre of the spontaneous breathing level [28, 29], probably describes the effects of two different sensations: the left limb describes air hunger, and the right limb describes work/effort [37].

\section{Neuromuscular disease}

In patients with neuromuscular disease (NMD), a normal inspiratory motor output per unit change in $\mathrm{PCO}_{2}$ results in a shallower breathing pattern [38]. The consequent impairment of neuroventilatory coupling underlies the high scoring of dyspnoea in these patients (fig. 1). In turn, the association of muscle weakness and elastic load in NMD is responsible for the modulation of a normal central respiratory output into a shallow pattern of breathing. Studies raise the possibility that NMD [38], COPD [20, 21], ILD [22] and airway involvement in multi-system disease [39] share common mechanisms underlying the discomfort associated with the act of breathing. A common underlying pathophysiological mechanism explains the similarity of clusters selected in different disorders [6].

LANINI et al. [40] showed that an increased inspiratory elastic load in stroke patients is translated into an increased inspiratory motor output (IMO). However, contrary to the initial hypothesis that in patients with abnormalities in respiratory mechanics an increase in IMO could translate into an increased perception of dyspnoea, the perception of dyspnoea was unexpectedly blunted in patients. This is probably because of the abnormality in the mechanisms of the process of integration of the afferent sensation. If the increased IMO does not transmit the corollary discharge to the

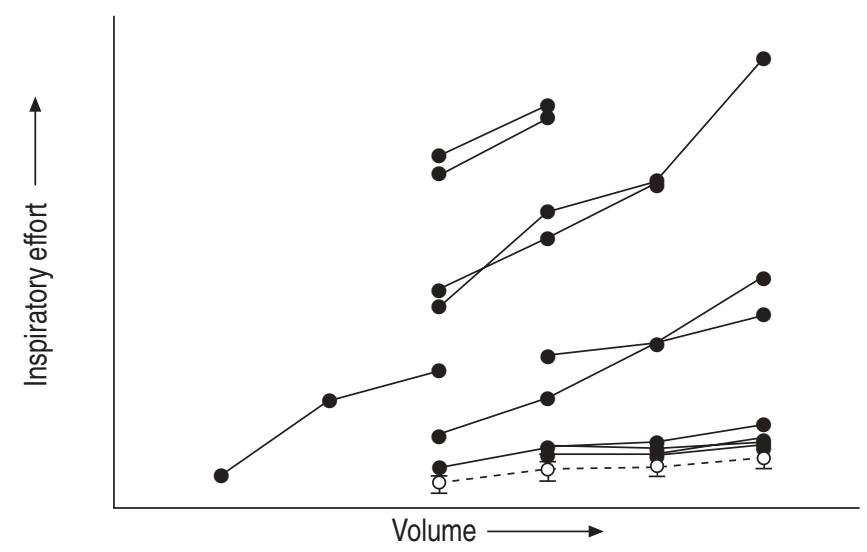

FIGURE 1. Schematic presentation of changes in inspiratory effort and volume. Increase in inspiratory effort was associated with an increase in dyspnoea. - : neuromuscular disease patients; $\bigcirc$ : control subjects. Modified from [40].

sensory centre, an unchanged perception may result. Might this be due to functional abnormalities of the sensory cortex? In this regard, PEIFFER et al. [41] performed a functional imaging study by positron emission tomography to identify brain region activation associated with an important component of respiratory discomfort during loaded breathing in healthy subjects. They found that highly loaded breathing was associated with neural activation of a distinct brain region identifying areas where regional blood flow was related to the mean amplitude of mouth pressure swings, and areas where neural activation was specifically associated with perceived intensity of respiratory discomfort that was not related to mouth pressure swings. PEIFFER et al. [41] speculated that the main activation areas are part of a neural network involved in the process of two parallel integrations: the genesis and perception of respiratory discomfort, and modulation of the perceived intensity. In turn, the hypothesis that damage to the sensory cortex attenuates the effect of the corollary discharge, which could influence a patient's ability to perceive dyspnoea, may not be excluded [40].

\section{Congestive heart disease}

Patients with chronic heart failure (CHF) complain of exercise limitation. When requested to describe their dyspnoea, they select the cluster "suffocating at rest", rapid breathing, air hunger [1], a "need to sigh" [2] or work/effort during exercise [5]. The explanation of the underlying pathophysiology is not easy because of the conflicting data reporting on whether respiratory function contributes to exercise limitation in $\mathrm{CHF}$ patients. CLARK et al. [42] have shown that these patients may stop exercising because of intolerable exertional dyspnoea, leg fatigue or both, at a point where there is apparent cardiopulmonary reserve.

O'DONNELL et al. [43] showed that inspiratory pressure support decreases leg effort, probably by reducing the left ventricular afterload, increasing peripheral blood flow and improving local acid-base equilibrium, which reduces muscular afferents associated with the perception of "effort". Nonetheless, the observation of no evident effect on dyspnoea 
during the constant load exercise test suggests that factors other than mechanical loading contribute predominantly to dyspnoea.

HAMILTON et al. [44], and more recently KiLLIAN [45] (in a larger series of 16.000 patients), have determined the mechanisms of exercise intolerance and the limiting complaints (dyspnoea or leg fatigue) in patients with angina, pulmonary impairment, ischaemic heart disease or cardiopulmonary disease. Their studies reveal a simple picture. When patients were subdivided according to exercise tolerance, the intensity of both dyspnoea and leg effort increased as exercise tolerance decreased for all disease types. The proportion of patients limited by dyspnoea, leg effort, or a combination of both was similar for all disease types. Only the angina group selected "chest pain". Verbal descriptors may help differentiate between patients with $\mathrm{CHF}$ and deconditioned patients who describe "heavy breathing" [46].

\section{CONCLUSIONS}

Although cultural, socio-economic, linguistic and educational backgrounds may influence the use of the language of dyspnoea, "our ability to provide the best care possible to patients with dyspnoea depends upon our capacity to break down any communication barriers between physician and patients" [46]. As dyspnoea is a fundamental part of a patient's clinical history, physicians should "become more fluent in the language of dyspnoea" [8]. Some questions have arisen after a number of studies have shown the positive effects of pharmacological treatment [47-52] and pulmonary rehabilitation programmes [53-58] on breathlessness in patients with chronic obstructive pulmonary disease. Should the various aspects of dyspnoea identified by verbal descriptors be independently quantified? Should improvement of the physiological derangements modify the language of dyspnoea? Should reduction of dynamic hyperinflation modify the relevant descriptor(s)? These points need to be investigated.

\section{REFERENCES}

1 Simon PM, Schwartzstein RM, Weiss JW, Fencl V, Teghtsoonian M, Weimberger SE. Distinguishable types of dyspnoea in patients with shortness of breath. Am Rev Respir Dis 1990; 142: 1009-1014.

2 Elliott MW, Adams L, Cockcroft A, Macrae KD, Murphy K, Guz A. The language of breathlessness: use of verbal descriptors by patients with cardiorespiratory disease. Am Rev Respir Dis 1991; 144: 826-832.

3 Banzett RB, Lansing RW, Brown R, et al. "Air hunger" arising from increased $\mathrm{PCO}_{2}$ persists after complete neuromuscular block in humans. Respir Physiol 1990; 81: $1-17$.

4 Banzett RB, Lansing RW, Reid MB, Adams L, Brown R. "Air hunger" arising from increased $\mathrm{PCO}_{2}$ in mechanically ventilated quadriplegics. Respir Physiol 1989; 76: 53-68.

5 Mahler DA, Harver A, Lentine T, Scott JA, Beck K, Schwartzstein RM. Descriptors of breathlessness in cardiorespiratory diseases. Am J Respir Crit Care Med 1996; 154: 1357-1363.

6 Killian KJ, Watson R, Otis J, St Amand TA, O'Byrne PM. Symptom perception during acute bronchoconstriction. Am J Respir Crit Care Med 2000; 162: 490-496.
7 Jones PW, Wilson RC. Cognitive aspects of breathlessness. In: Adams L, Guz A, eds. Respiratory sensation. New York, Marcel Dekker, 1996; pp. 311-339.

8 Mahler DA, Harver A. Do you speak the language of dyspnoea? Chest 2000; 117: 928-929.

9 Petit JM. Afferent pathways. In: Porter R, ed. Breathing. Hering-Breuer Centenary Symposium. London, J\&A Churchill, 1970; pp. 111-124.

10 Paintal AS. Vagal receptors and their reflex effects. Physiol Rev 1973; 53: 159-227.

11 Taguchi O, Kikuchi Y, Hida W, et al. Effects of bronchoconstriction and external resistive loading on the sensation of dyspnoea. J Appl Physiol 1991; 71: 2183-2190.

12 McCluskey DI. Corollary discharges: motor commands and perception. In: Brookhart JM, Mountcastle VB, eds. The nervous system. Handbook of Physiology Section 1, Vol. 2, Part 2. Bethesda, American Physiological Society, 1981; pp. 1415-1447.

13 Gandevia SC. Neural mechanisms underlying the sensation of breathlessness: kinesthetic parallels between respiratory and limb muscles. Aus N Z J Med 1988; 18: 83-91.

14 Schwartzstein RM, Simon PM, Woodrow Weiss J, et al. Breathlessness induced by dissociation between ventilation and chemical drive. Am Rev Respir Dis 1989; 139: 1231-1237.

15 Manning HL, Schwartzstein RM. Pathophysiology of dyspnoea. New Engl J Med 1995; 33: 1547-1552.

16 Killian KJ, Campbell EJM. Dyspnoea. In: C Roussos, ed. The thorax part B. New York, Dekker, 1995; pp. 17091747.

17 Binks AP, Moosavi SH, Banzett RB, Harver A, Mahler DA, Schwartzstein RM. "Tightness" sensation of asthma does not arise from the work of breathing. Am J Respir Crit Care Med 2002; 165: 78-82.

18 Lougheed MD, Flannery J, Webb KA, O'Donnell DE. Respiratory sensation and ventilatory mechanics during induced bronchoconstriction in spontaneously breathing low cervical quadriplegia. Am J Respir Crit Care Med 2002; 166: 370-376.

19 O'Donnell DE. Breathlessness in patients with chronic airflow limitation: mechanisms and management. Chest 1994; 106: 904-912.

20 O'Donnell DE, Bertley JC, Chau LL, Webb KA. Qualitative aspects of exertional breathlessness in chronic airflow limitation: pathophysiologic mechanisms. Am J Respir Crit Care Med 1997; 155: 109-115.

21 O'Donnell DE, Revill SM, Webb AK. Dynamic hyperinflation and exercise intolerance in chronic obstructive pulmonary disease. Am J Respir Crit Care Med 2001; 164: 770-777.

22 O'Donnell DE, Chau LKL, Webb AK. Qualitative aspects of exertional dyspnoea in patients with interstitial lung disease. J Appl Physiol 1998; 84: 2000-2009.

23 Harty ER, Corfield DR, Schwartzstein RM, Adams L. External thoracic restriction, respiratory sensation, and ventilation during exercise in men. J Appl Physiol 1999; 86: 1142-1150.

24 Adrian ED. Afferent impulses in the vagus and their effect on respiration. J Physiol (Lond) 1933; 70: 332-358. 
25 Davies A, Dixon M, Callahan D, Huszczuk A Widdcombe JG, Wise JCM. Lung reflexes in rabbits during pulmonary stretch receptor block by sulphur dioxide. Respir Physiol 1978; 34: 83-101.

26 Chonan T, Mulholland MB, Leitner J, Altose MD, Cherniack NS. Sensation of dyspnoea during hypercapnia, exercise and voluntary hyperventilation. I Appl Physiol 1990; 68: 2100-2106.

27 Demediuk BH, Manning H, Lilly J, et al. Dissociation between dyspnoea and respiratory effort. Am Rev Respir Dis 1992; 146: 1222-1225.

28 Chonan T, Mulholland MB, Altose MD, Cherniack NS. Effects of changes in level and pattern of breathing on the sensation of dyspnoea. J Appl Physiol 1990; 69: 1290-1295.

29 Brack T, Jubran A, Tobin M. Dyspnoea and decreased variability of breathing in patients with restrictive lung disease. Am J Respir Crit Care Med 2002; 165: 1260-1264.

30 Pride NB, Macklem PT. Lung mechanics in disease. In: Fishman AP, ed. Handbook of physiology. Section 3, Vol. 3, part 2: The respiratory system. Bethesda, American Physiological Society 1986; pp. 659-692.

31 Lougheed MD, Lam M, Forkert L, Webb KA, O'Donnell DE. Breathlessness during acute bronchoconstriction in asthma. Am Rev Respir Dis 1993; 148: 452-459.

32 Moy ML, Woodrow Weiss J, Sparrow D, Israel E, Schwartzstein RM. Quality of dyspnoea in bronchoconstriction differs from external resistive loads. Am J Respir Crit Care Med 2000; 162: 451-455.

33 Gorini M, Iandelli I, Misuri G, et al. Chest wall hyperinflation during acute bronchoconstriction in asthma. Am J Respir Crit Care Med 1999; 160: 808-816.

34 Moy ML, Latin ML, Harver A, Mahler DA, Schwartzstein RM. Language of dyspnoea in assessment of patients with acute asthma treated with nebulized albuterol. Am J Respir Crit Care Med 1998; 158: 749-753.

35 Harver A, Mahler DA, Schwartzstein RM. Use of a descriptor model for prospective diagnosis of chronic dyspnoea. Am J Respir Crit Care Med 2000; 161: A705.

36 O'Donnell DE, Hong HH, Webb KA. Respiratory sensation during chest wall restriction and dead space loading in exercising men. J Appl Physiol 2000; 88: 1859-1869.

37 Lansing RW, Im BS-H, Thwing JI, Legedza ATR, Banzett RB. The perception of respiratory work and effort can be independent of the perception of air hunger. Am J Respir Crit Care Med 2000; 162: 1690-1696.

38 Lanini B, Gigliotti F, Coli C, et al. Dissociation between respiratory effort and dyspnoea in a subset of patients with stroke. Clin Sci 2002; 103: 467-473.

39 Scano G, Seghieri G, Mancini M, et al. Dyspnoea, peripheral airway involvement and respiratory muscle effort in patients with type I diabetes mellitus under good metabolic control. Clin Sci 1999; 96: 499-506.

40 Lanini B, Misuri G, Gigliotti F, et al. Perception of dyspnoea in patients with neuromuscular disease. Chest 2001; 120: 402-408.

41 Peiffer C, Poline JB, Thivard L, Aubier M, Samson Y. Neural substrate for the perception of acutely induced dyspnoea. Am J Respir Crit Care Med 2001; 163: 951-957.
42 Clark AL, Sparrow JL, Coates AJS. Muscle fatigue and dyspnoea in chronic heart failure: two sides of the same coin? Eur Heart J 1995; 16: 49-52.

43 O'Donnell DE, D'Arsigny C, Raj S, et al. Ventilatory assistance improves exercise endurance in stable congestive heart failure. Am J Respir Crit Care Med 1999; 160: 1804-1811.

44 Hamilton AL, Killian KJ, Summers E, Jones NL. Muscle strength, symptom intensity, and exercise capacity in patients with cardiorespiratory disorders. Am J Respir Crit Care Med 1995; 152: 2021-2031.

45 Killian KJ. The mechanisms of dyspnoea. Eur Respir Rev 2002; 82: 31-33.

46 Schwartzstein RM. The language of dyspnoea. Eur Respir Rev 2002; 82: 28-30.

47 Belman MJ, Botnick WC, Shin W. Inhaled bronchodilators reduces dynamic hyperinflation during exercise in patients with chronic obstructive pulmonary disease. Am J Respir Crit Care Med 1996; 153: 967-975.

48 O'Donnell DE, Lam M, Webb A. Measurement of symptom, lung hyperinflation, and endurance during exercise in chronic obstructive pulmonary disease. Am J Respir Crit Care Med 1998; 158: 1557-1565.

49 Ayers ML, Mejia R, Ward J, Lentine T, Mahler DA. Effectiveness of salmeterol versus ipratropium bromide on exertional dyspnoea in COPD. Eur Respir J 2001; 17: 1132-1137.

50 Ambrosino N, Scano G. Measurement and treatment of dyspnoea. Respir Med 2001; 95: 539-547.

51 Taub C, Lehnigk B, Paasch K, Kirsten DK, Jorres RA, Magnussen H. Factor analysis of changes in dyspnoea and lung function parameters after bronchodilation in chronic obstructive pulmonary disease. Am J Respir Crit Care Med 2000; 162: 216-220.

52 Nishino TN, Ide T, Sudo T, Stao J. Inhaled furosemide greatly alleviates the sensation of experimentally induced dyspnoea. Am J Respir Crit Care Med 2000; 161: 1963-1967.

53 O'Donnell DE, McGuire M, Samis L, Webb KA. The impact of exercise reconditioning on breathlessness in severe chronic airflow limitation. Am J Respir Crit Care Med 1995; 152: 2005-2013.

54 American Thoracic Society. Dyspnea: Mechanisms, assessment, and management: a consensus statement. Am J Respir Crit Care Med 1999; 159: 321-340.

55 Gigliotti F, Coli C, Bianchi R, et al. Exercise training improves exertional dyspnea in patients with COPD: evidence of role of mechanical factors. Chest 2003; 123: 1794-1802.

56 Bianchi R, Gigliotti F, Romagnoli I, et al. Chest wall kinematics and breathlessness during pursed lip breathing in patients with COPD. Chest 2004; 125: 459-465.

57 Gosselink R, Decramer M. Muscle training in pulmonary rehabilitation. In: Donner CF, Decramer M, eds. Pulmonary rehabilitation. Eur Respir Mon 2003; 123: 99-110.

58 Emtner M, Porszasz J, Burns M, Somfay A, Casaburi R. Benefits of supplemental oxygen in exercise training in nonhypoxemic chronic obstructive pulmonary disease patients. Am J Respir Crit Care Med 2003; 168: 1034-1042. 